\title{
Bleeding in Public? Rethinking Narratives of Menstrual Management from Delhi’s Slums
}

\author{
Annie McCarthy and Kuntala Lahiri-Dutt
}

Flowing from inside the body to out, menstrual blood is experienced in both public and private realms-where hierarchies of gender, knowledge, and power position menstruators ${ }^{1}$ as responsible for, but not always in control of, the meanings attached to their own bodies. Menstruating bodies are, thus, both objects and agents, where agency is at once the agency of the body as an independent actor that is not always or easily controlled and agency over the body (Fingerson 2006, 23). As "both the objects and subjects of their bodies, of menarche and menstruation" (Puri 1999, 43), menstruators are positioned betwixt and between the public and the private (see Vora [Chapter 4] in this volume). Experiences of menstruation, while deeply personal and embodied, also have an external biomedical framing; menstrual blood is a private secret that is expected to be concealed (see Wood [Chapter 25] in this volume), yet menarche can have radical implications for a girl's lifestyle and mobility (Jewitt and Ryley 2014; Puri 1999). Hygiene is considered an individual pursuit-yet, in the absence of sanitation infrastructure, it becomes a public issue. The shifting meanings and values assigned to 'public' and 'private' across regimes of knowledge, culture, and environment are, thus, the key to understanding experiences of menstruation in any context. To illustrate the salience of these ideas for Menstrual Hygiene Management (MHM) in the Indian context, this chapter analyzes the gendered challenges of everyday life in informal settlements in Delhi. We explore the experiences of women and girls who manage menstruation in conditions of extreme congestion to argue that the way privacy is conceived of in MHM initiatives-as self-evidently material-erases the complex ways privacy is socially constructed, gendered, and layered with power dynamics. To draw out these points, this paper will 
first introduce the deficit framing of MHM in India and then move through a discussion of key themes: privacy, space, and knowledge before introducing the water and sanitation issues faced in Delhi. Subsequently, it will more explicitly introduce the context of informal settlements in Delhi, before lastly focusing on a particular settlement and the story of one woman: Champa.

This chapter brings together the findings and insights of a number of research projects. The first author draws on her experience of fieldwork with children from four slum communities in Delhi, in which she documented the ways these children and their communities were framed by sanitation and hygiene promotion campaigns (see McCarthy 2015). The second author contributes specific data on women's experiences of menstruation, collected through long interviews, focus group discussions, and participant observation carried out in one particular slum cluster in the New Okhla Industrial Development Authority (NOIDA). The women in this latter study group were selected on the basis of familiarity developed from earlier research.

\section{INDICATING DEFICITS}

When engaging with the MHM literature on India, one is invariably and immediately bombarded with a range of 'alarming' statistics that starkly highlight the 'deficiencies' in Indian women's and girls' menstrual knowledge and practices. These studies report statistics such as $88 \%$ of menstruating women in India use fabric, rags, ash, straw or wood shavings to absorb their menstrual flow; " $70 \%$ of mothers consider menstruation 'dirty,' perpetuating a culture of shame and ignorance. . . . Girls are typically absent for $20 \%$ of the school year due to menstruation"; and poor menstruation hygiene practices cause a "70\% increase in incidence of reproductive tract infections" (USAID, Kiawah Trust, and Dasra 2014, 2). In these studies, individual experiences of menstruation, studied in a specific context, are transformed into numerical data sets that circulate globally to justify interventions largely focused on poor and marginalized women in the Global South. Key indicators ${ }^{2}$ informing these data sets are knowledge of menstruation at menarche; use of menstrual products; days absent from school or work as a result of menstruation; rates of reproductive tract infections (RTIs); access to clean water and toilet facilities; experience of menstrual taboos; and methods of disposing absorbents (see Rajagopal and Mathur 2017; Mahon and Fernandes 2010; Kumar and Srivastava 2011 for Indian examples). These indicators, taken together, transform menstruation into a series of milestones and practices that can be assessed against global rubrics of health, dignity, education, and productivity (for one example see Sommer 2010). Yet, the benevolence and utilitarianism of this language obscures the fact that these indicators are embedded in specific contexts, and that a variety of structural, religious, cultural, and gendered practices - that both construct and obstruct the 'management' of menstruation-are involved in determining an individual's menstrual management practices. 
Rather than any specific engagement with these local meanings of menstruation, contemporary MHM initiatives emerging out of transnational human rights and development discourses, assume a universal human subject with rights to 'dignity,' 'privacy,' 'hygiene,' 'health,' and 'productivity.' While claiming universality, each of these terms has a unique history that cannot be separated from the violent construction of colonized, feminized, 'dirty,' 'lazy' bodies as the 'other' against which first colonial, and later developmentalist projects were created and sustained. Today, alongside 'health' it is the paradigm of dignity that is the key discursive tool mobilized by contemporary MHM initiatives (for examples see Mahon and Fernandes 2010; Phillips-Howard et al. 2016 and for a critique see Bobel 2019). Yet the discursive production of 'indignity' in studies on MHM in India necessitates critiques similar to those mounted by Bhaskar Mukhopadhyay (2006) in his attack on Arjun Appadurai's (2004) 'apologia' of World Bank programs targeting open defecation. Mukhopadhyay (2006, 227) accuses Appadurai of "maintaining the moral purity of categories - dignity, humiliation, purity, pollution, right, wrong" at the expense of excluding "a more porous field of responses." Mukhopadhyay (2006) suggests that in abandoning these pure categories, we should not ignore the 'problem' but, instead, engage "with popular or subaltern practices as ethico-political responses and [reflect] on their sources of authority rather than simply denigrating them from the vantage point of some absolute wisdom (227)." This kind of commitment informs our approach, particularly our representation of women's and girls' practices of managing menstruation in the latter half of this paper.

\section{Managing Privacy and Knowledge}

The translation of 'individual' practices into indicators used to promote standardized education and MHM campaigns forces us to re-examine the language of 'management' and ask "who is doing the managing?" and "what exactly is it that they are managing?" Lahiri-Dutt's (2015) critique of MHM projects suggests that these programs aim to 'empower' menstruators to manage their periods as individual, private concerns free from social taboos or stigma. Yet underlying these efforts are a set of assumptions about the positive relationship between privacy, bodily autonomy and empowerment, and negative connotations of 'public' as the space where stigma and restriction are imposed. This binary - and the responsibility it places on women to 'manage' their own bodies rather than on society to 'manage' its expectationshave long been challenged by feminist and radical menstruation activists both in the West (see Bobel 2010) and more recently in India where there has been a recent spate of menstruation-related activism (Prasanna 2016; Fadnis 2017). These recent campaigns in India have confronted restrictions on entering places of worship while menstruating and government taxes on menstrual products. The latter have involved challenging public stigma around menstruation by brandishing bloody pads and mobilizing hashtags 
like \#DontTaxMyPeriod (Fadnis 2017) to oppose the very real nexus of gendered violence, capitalism, and medicalization that makes bleeding bodies a 'problem.' Yet outside of these moments that intentionally orchestrate the private 'bleeding over' into the public, everyday experiences of menstruation in India are similarly saturated with complex violences that are neither entirely public nor completely private, entirely biological or cultural, familial, or individual. Jyoti Puri's (1999) work among middle-class Indian women speaks to this tension. Bitter tales of the rules and restrictions imposed post menarche intertwine with individual impulses to conceal and individually manage menstruation. These stories point to the impossibility of containing menstruation within the bounds of an individual body, and force us when considering experiences of menstruation in informal settlements to interrogate global development funders' MHM interventions that largely seek to render menstruation a 'technical' problem with technical solutions ( $\mathrm{Li} 2007){ }^{3}$

Congestion is a defining feature of life in informal settlements and plays a powerful role in shaping the lives of women and girls affecting their personal care, physical and mental well-being (see Reddy and Snehalatha 2011; Joshi, Fawcett, and Mannan 2011). These cramped conditions also contribute to the reconfiguring of the very notion of privacy itself. Thus, in informal settlements, privacy is not necessarily a material space but a technique of modulating, or even countering forces of social control. Indeed, Gan $(2009,3)$ observes that "in a rigid social environment, privacy preserves a small breathing space, providing privacy from others while also enabling self-expression, the privacy to do something else or to be someone else." Following Moore's $(1984,6)$ definition of privacy as "a desire for socially approved protection against painful social obligations," we are reminded of the ways that privacy for women in informal settlements produces spaces for an alternative identity that is different from their traditional domestic role or their role as wage earners. Women in informal settlements in Delhi are typically migrants from rural areas, who, on entering the sprawling urban metropolis, find themselves surrounded by rapid-paced social change. Thus, following Gan's $(2009,3)$ argument-that privacy is a way to shield oneself from the grasping hand of social convention-we argue that rural women moving into the congested metropolis utilize techniques for the production of privacy to protect themselves from the impact of change and to pause and reconsider their place in the social mosaic. Here privacy is not the ability to be alone with or have full control over one's body, but is enabled by a series of techniques and practices that assert a claim to autonomy and identity that is neither entirely spatial nor social. Ayona Datta's (2008) reflections on her fieldwork in informal settlements in Delhi reminds us that gender is key to these practices, forcing us to recognize how "intimately the materialities of bodies and bodily performances are connected to masculine or feminine marking of places, and how these are regulated and given form through narratives and discourses (202)." 
Yet these local narratives and discourses are framed as at best irrelevant and at worst outright dangerous by MHM initiatives in India that highlight deficiencies in girls' knowledge of menstruation prior to menarche. Studies of Indian girls have found that anywhere between 35 and $81 \%$ of girls surveyed are unaware of menstruation prior to menarche (see Van Eijk et al. 2016; USAID, Kiawah Trust, and Dasra 2014; Rajagopal and Mathur 2017; Zaidi, Sivakami, and Ramasamy 2015; Bhattacherjee et al. 2013). Noting this lack of knowledge, many of these studies go on to comment on the source and 'quality' of the knowledge these women and girls do possess (see Van Eijk et al. 2016; Dasgupta and Sarkar 2008). These studies emphasize how the lack or 'poor quality' of girls' knowledge leads to distress, typically by describing how menarche triggers anxiety, panic, fear, and worries about imminent death. One study in Ranchi notes that among the slum girls surveyed, 54.5\% were frightened and cried (Kumar and Srivastava $2011,596)$. Yet in these studies this distress is not linked to bodily changes but an 'ignorance' of biological process that produce them. This discourse of ignorance-as-inevitably-causing-distress leads to the double victimization of women and girls as subject not only to their own bodies, but also to the ignorance of their own families and communities. Local ways of knowing about menstruation are further stigmatized by being labeled cultural and religious, and are framed almost entirely through the twin lenses of taboo and restriction. Following Mohanty's (1984) classic text on the production of 'third world difference,' we argue that such studies reinscribe the object status of these girls and women and in the process affirm teachers, public health officials, and development workers as the only true 'subjects' of MHM interventions (for examples of this see Rajagopal and Mathur 2017; Kumar and Srivastava 2011). While we acknowledge that efforts to improve menstrual literacy are important, we suggest they must be framed in ways that acknowledge local knowledges and stop short of privileging outsider expertise as inherently superior.

\section{WASHiNG IN DELHI ${ }^{4}$}

Although constantly welcoming new inhabitants, many of Delhi's slums are decades old. From the beginning, "the building of planned Delhi was mirrored in the simultaneously mushrooming of the unplanned Delhi" (Baviskar 2003, 91). Today in Delhi, estimates of the population of slum settlements, officially called jhugg $\bar{\imath}$ jhopri $\bar{\imath}(\mathrm{JJ})$ clusters, ${ }^{5}$ range from $15 \%$ to over $50 \%$ of the urban population (Ghertner 2015,6$)$. This numerical uncertainty is both produced by and, in turn, produces spaces of infrastructural neglect, where informality is equated with illegality and slum dwellers are stigmatized as 'migrants' deemed ineligible to share civic rights to the modern city (Ghertner 2015; Baviskar 2003; Datta 2012). Growing voices of discontent, powerfully mobilizing through Resident Welfare Associations (RWA), argue that slums are unsightly stains on the city, the last remnants of which 
have to be erased for Delhi to take its rightful place on the global stage (see Baviskar 2003; Bhan 2009; Datta 2012; Ghertner 2015). But such narratives of slums - as sites of filth and disease, as obstacles to development and modernity - are far older than the post-independence mushrooming of Delhi, and far more widespread. These have their origins in the colonial period when "doctors and surgeons helped to form and give seemingly scientific precision to abiding impressions of India as a land of dirt and disease, of lethargy and superstition, of backwardness and barbarity" (Arnold 1993, 292). When in 1888 Viceroy Lord Dufferin requested a general inquiry into the hygiene habits of India, colonial officials in their report wrote "to the masses of the people . . s sanitation is foolishness" (Prashad 2002, 47-48). But sanitation became "foolishness" as Prashad (2001) persuasively argues for colonial Delhi, precisely because the British pathologized Indians as impossibly dirty and declined to spend money on modern sanitation infrastructure.

Contemporary WASH initiatives targeting informal settlements in Delhi articulate many of the same issues and doubts as Delhi's colonial administrators. Here questions about the attitudes and dispositions of the 'unclean' combine with the practical difficulties of making infrastructural changes in dense settlements to produce both a systematic disinclination, as well as financial and bureaucratic barriers that prevent many of the innumerable small NGOs who have mushroomed in Delhi in recent years from engaging in costly infrastructure projects (one example of an organization encountered by McCarthy during her fieldwork is WASH United). ${ }^{6}$ This lack of engagement is stark considering that the urban poor in Delhi have "particularly vulnerable water access . . . millions lack official connections or even rights to public water supplies" (Truelove 2011, 147). Yaffa Truelove (2011) notes that even when available the "water supply is marked by such dramatic unreliability that the majority of residents engage in informal and supplemental water sources and practices" (147). Despite these gaps, many interventions into WASH by small NGOs witnessed by McCarthy during her fieldwork in Delhi in 2013 occurred entirely at the level of education and behavior change. These programs create a trap, in which slum dwellers without access to adequate sanitation infrastructure can never be clean enough to shatter ideas of their innate proclivity toward filth, nor adequately demonstrate their desire and worthiness to be given the infrastructure that would allow them to be 'properly clean.' Seemingly stuck in this endless cycle of education campaigns, slum dwellers drift in and out of WASH initiatives that, just like the handwashing promotion campaign studied by McCarthy (2015) do not provide soap nor address issues of water accessibility.

In the context of MHM, these education programs are mostly silent about one of the key biomedical facts of menarche: fertility. This is rather ironic given that, as Emily Martin (1999) has shown, the biomedical paradigm of menstruation is one of failed reproduction. This becomes even more paradoxical in the context of informal settlements in which a girl's newly attained fertility is the driving force behind efforts to control or constrain her 
movements in ways that ensure the preservation of her family's izzat (honor/ integrity), preserve the possibilities for arranging a 'good' marriage, and ensure that both the daughter and her family do not become the subjects of cruel community gossip (see Chakraborty 2010). A training manual developed by the Water Supply and Sanitation Collaborative Council (WSSCC) in collaboration with the Government of India $(2013,31)$ explicitly advises trainers to de-link the "teaching of sex education from training in menstrual hygiene practices, to avoid causing ethical or religious offense." But this focus on menstruation as solely a "hygiene crisis" actively ignores many of the local social and moral meanings attached to menstruating bodies (Bobel 2019, 295).

In the context of informal settlements, moral and social meanings are equally inscribed in local infrastructure and resources, often in deeply gendered ways. In the communities in which McCarthy worked in 2013, water was the greatest source of community tension; neighbors continually evaluated each other's 'private' water use, misuse, or overuse in moral terms. In one slum community, girls vehemently denounced their neighbors' water use, framing whole families as selfish and only able to think of themselves. An individual's or family's, use or perceived misuse of shared resources-water pumps and public toilets-becomes thickly layered with moral significance; people consider others 'good' or 'bad' based on their usage of resources. Yet the necessity of using these 'public' resources, means that sanitation, in particular, the care of the menstruating body, in this context cannot be reduced to an individual 'private' project. Specifically, this moral quality means that 'privacy,' if conceived of spatially, is not just a question of being able to conceal one's body and its processes, such as menstruation, but also the ability to shield oneself from the nexus of community observation and gossip. Yet returning to Moore's (1984) definition of privacy as a "socially approved protection" (6) understanding privacy simply in terms of spatiality does not do justice to the extent to which community relations and gendered forms of participation in networks of sharing and speaking construct meaningful personhood in these communities. To explore this further let us now explore the space of one informal settlement in Delhi.

\section{NoIDA}

In and around NOIDA, the popular acronym for New Okhla Industrial Development Authority, informal JJ clusters number between 200 and 310, with an additional 150-180 in the areas around Greater NOIDA. Each cluster may have 20-50 jhuggis or dwellings, although often, there are several jhuggis on a single plot of land. Living in these various communities are about $8000-10,000$ women, most of whom work as domestic helpers in middle-class residences. Typically working between 5 a.m. and 9 p.m., these women earn between INR 15,000 and INR 18,000 (USD 300-USD 360) a month. Having migrated from the Indian states of Uttar Pradesh, Bihar, and West Bengal—and also from Bangladesh—these predominantly low-caste 
women live in these slum settlements to work for the period of time it takes to save up to build a pakka (concrete) house in their home village or to save for their children's marriages. In slum communities in NOIDA 20 or 30 people share a common latrine-made of bamboo sticks and tarpaulin with holes in the bottom to carry the excrement to the nearby field. In these communities, each shanty home has three sections: a front, a middle, and a back. The small front section, made of bricks on the mud, is used for washing dishes and clothes; some women take their bath here-in their sari. This affords them some privacy - only their husband and children can come here, or see them. Then there is a small, canopied area where the family sleeps during the hot, humid summer, or entertains house guests, particularly men. At the very back is the family's private area-possibly a wooden bed, with a mosquito net; and a shelf, or a box, that contains the family's personal possessions. This rudimentary division of space is one technique of producing privacy that demonstrates both its spatial, social, and gendered characteristics.

\section{CHAMPA}

Champa, a woman of around 32 years, lives with her husband and two children in such one settlement. Champa is from West Bengal. There is no government school for children living in this informal settlement, so her children do not go to school. Champa and her husband go out to work in the day, and the children cannot stay at home by themselves, so Champa takes them along to work. Sometimes they also help her with household chores or help their father collect and recycle garbage. Champa's son, 11 , is good at sweeping and scrubbing. She proudly recounted how her son often mocks her cleaning: "How do you clean rich people's houses? How could they take your work and not complain?" Cleanliness and hygiene is, thus, a matter of pride for Champa and her son, who asserts his own claims to hygienic standards higher than his mothers. ${ }^{\text {? }}$

While menstruating, Champa, like other women in the cluster, uses homemade napkins made from rolled up sections of old cloth. She says old cloth is soft. Champa uses stronger fabrics, such as sari borders, to make a string to hold the roll in place. She throws away the cloth after one use; she never reuses the cloth because, unlike in her village, it is impossible to wash the used cloth in the cramped conditions of the shanty colony or in its crowded bathing place. When we asked how she ensured a steady supply of old saris, Champa said that she received old saris as gifts. She added that in the harsh weather of Delhi, the saris do not last long, soon becoming ready for use as rags. There are several waste bins that the slum community has set up and usually the garbage is burned by the community when the bins start to overflow. When she puts on the cloth in her shanty, her husband stands guard outside to ensure her privacy. She puts on one cloth bundle before starting work early in the morning. She is often busy during the better part of the day, and is only able to change the pack after her late afternoon shower. 
The role of husbands in assisting women with managing their menstruation was commonly reported during our focus groups. This points to the way privacy in this context is something that is relationally constructed, both along and across gendered lines. Yet that the couple collaborates to manage menstruation dismisses many beliefs of gender-based separation of malefemale domains that are prevalent in feminist discourse.

Champa cannot reuse her cloths, as many Indian women do, because she lacks privacy and access to resources to wash and dry cloths. MHM experts deplore the practice of reusing homemade 'sanitary napkins' particularly when they cannot, as is typically the case in informal settlements, be dried properly in full sunlight (for an example of this rhetoric see Mahon and Fernandes 2010). While public health experts stress that sunlight removes all traces of dampness and has a sterilizing effect, in cramped slum communities exposing one's cloths to the sun would also mean exposing the fact of one's menstruation to the community. Reuse of improperly clean and dried cloths is in much MHM literature cited as a key factor of recurrent and dangerous RTI, yet this is an assumption that has been questioned in a systematic review (see Sumpter and Torondel 2013 for both examples and refutation). Despite this recent research, many MHM initiatives would likely celebrate Champa's adoption of single-use absorbents. Yet such an evaluation would fail to take into account the broader ways the overcrowding in Champa's settlement, its stretched water resources, the role of her husband in securing her privacy, and her labor to continually source and make new cloths to absorb her menses, structure her life. By ignoring these social, infrastructural, and interpersonal conditions actually required to 'manage' menstruation, any simple celebration of the use of single-use absorbents in this context would fail to recognize the extent to which local menstrual management practices cut across public and private domains, configuring Champa as both an agent and something that is acted upon. If Champa had greater access to privacy, no doubt she would reuse her cloths, as many other Indian women do. This, in itself, should provoke us to think further about the politics of defining experiences of 'lack,' and to look further into the ways value is assigned to particular practices in particular contexts. Additionally, it forces us to ask, with Barbara Penner (2010): "When is provision good enough, dignified enough? And who decides?"

\section{Changing Meanings of Menstruation Over the Life Course}

The simultaneously public and private nature of menstruation was further borne out during a focus group discussion with eight, initially reluctant, women living in the JJ cluster. To attempt to alleviate this discomfort we started asking these women about experiences of menarche of girls in their community. Women in our focus group said that girls in this community get their period between the ages of 10 to 12 . When they lived in the village, simple stree achar (feminine rituals) were performed to mark a girl's puberty and menarche. 
While these rituals have been altered or simply omitted in the new context of the slum (see Hawkey, Ussher, and Perz [Chapter 10] in this volume), the onset of menstruation nonetheless sends out a 'warning' signal to a girl's parents. In the village, as soon as the girl reaches puberty, the elders in the family began to alert the parents to start looking for a groom, to protect her virginity. Within a year or two of her first period, the girl will be married (see Sawo [Chapter 9] in this volume). In the slum, keeping a menstruating girl unmarried and at home for long is considered neither safe for the girl nor the family who must bear the burden of an unexpected pregnancy from a love affair or rape. While marriage is still considered the 'only' option for many families, growing discourses of girls' education and awareness of laws prohibiting child marriage place many slum-dwelling families in precarious positions in relation to their teenage daughters who themselves are increasingly educated about their rights in local NGO programs teaching girls' empowerment. For this generation of girls who have lived more of their life in the slum than the village and have often spent years in NGO programs cultivating educational and career aspirations, menstruation can signal much larger contestations about the meanings of childhood and adulthood.

As a woman matures however, the significance of her menstruation changes. Women told us that a housewife in a village experiencing menstruation is seen as a body that needs to rest: she is not meant to enter the mandir (temple; or, at home, the corner where the idols are housed) or perform puja (worship) (see Cohen [Chapter 11] as well as Sukumar [Chapter 13] in this volume). She is not expected to go outdoors or mingle with others, and she is expected to rest in a room alone during those four days. Married women abstained from cooking for their families on those four days, and other women had to take up these tasks. In a large joint, or extended, family, this does not pose a problem, as extra hands are always around. In a village, menstruation tends to bind a woman's body and her activities to a private space. Rather than seeing this entirely through the paradigm of 'restriction' and thus, negative gendered constructions of 'cleanliness' and 'purity,' we must realize the ways these practices allowed women to rest completely for four days and offered their bodies a break from relentless labor. This other side of 'confinement' is that the necessity of contributing labor and its subsequent income to their smaller family units in Delhi, meant most women in slums avoided taking time off during menstruation. Yet even though they did not take this time off, women continued to engage in practices of cleansing the body post menstruation, that would have previously initiated their return to everyday life. Thus, in spite of difficulties accessing water, and as testament to the importance of this ritual, most women wash their hair and clean their body once their period is over.

Older women in the focus group noted that menstruation necessitated non-participation in devotional activities but also allowed them to avoid having sex with their husbands. Younger women agreed: "When we are in the village", Champa said, "a husband does not come near the woman who is having her period, sex is completely forbidden." However, once couples 
are in the slum away from the joint family social controls are loosened, and husbands expect their wives to have sex on demand. From our discussions, this seemed to be one of the primary reasons of quarrels and ensuing fights, leading to violence between couples in the slum. Here competing demands made on the female body highlight tensions between reproductive labor and productive labor that women in informal settlements had to continually renegotiate in new settings far from their broader kin networks and the gendered norms that defined them.

These selected stories, drawn from across spaces of the rural and urban and of adolescence and wifehood illuminate the ways menstruation-its broad socio-cultural meaning and its management at the bodily level-cannot be regarded as a singular or static process, but rather one that is mediated across the life course, through relations with others, by configuring and reconfiguring space and by navigating expectations of productive and reproductive labor.

In these communities, young girls look up to their mothers to teach them about self-care, and to their mother-in-law after marriage. In other words, knowledge about menstruation management is transmitted generationally. While their current location-far from their home village, state, or countrycan and does disrupt traditional celebrations, cultural, familial, and generational knowledge of menstruation and related practices continue to be important even as they are challenged. Consequently, these resources-such as the stories shared in our focus groups documenting collaboration, nostalgia, and emerging spaces of contestation-remain major keys to understanding women's narratives of menstrual management practices. Largely deemed insufficient when examined through biomedical and hygienic lenses, this knowledge and the stories which encode it are fact deeply valued by women, and constitutes the first and primary site of information, meaning-making and support for most women. Returning to Mukhopadhyay $(2006,227)$ we must ask ourselves what it would mean to stop "denigrating" this knowledge "from the vantage point of some absolute wisdom" and engage with it as a form of agency imbued with clues to what women and their communities value and seek.

\section{Conclusion}

As we have shown, women's own voices have for a long time been ignored in debates about and interventions into women's MHM practices. In highlighting interventions that denigrate women's experiences and knowledge, we seek to challenge contemporary MHM initiatives and the extent to which they preserve and produce powerful discourses of 'third world difference' (Mohanty 1984). We argue that in Delhi's informal settlements, women who are marginalized across multiple axes of class, caste, and gender face daily struggles to claim recognition and access to the city's resources. We suggest that we can learn important lessons by drawing on the conversations with Champa and other women who constantly manage these structural deficits 
alongside the discourses of deficiency that are used to frame their lives. These women who were nostalgic for the menstrual management practices of village life and the corresponding period of rest force us to recognize that "women's participation in gender-traditional religions" may not signify passivity (Talukdar 2014, 141). Thus, by paying attention to forms of knowledge transmission and meaning-making of the kind expressed by these women we can better understand women's lived experiences of menstrual 'management.'

These meanings are shaped by environmental factors-rural $p s$ urban settings, joint families $v s$ nuclear, private $v s$ public access water-and how notions of public and private are reconfigured and remade in informal settlements. As women in the focus group noted, once in the city, the special significance attributed to menstruation's monthly occurrence is remarkably reduced, and other things, such as the commitment to be at the place of work on time, begin to dictate the daily rhythm of life. The absence of a clearer distinction between private and public spaces within jhuggis, and the JJ clusters more broadly, means that new meanings are attributed to spaces, new ways of performing everyday practices are imagined and invented, and menstruation begins to assume and convey new connotations. Yet, these practices are not fixed, they change constantly, as women and men-living in extremely congested conditions that often provide no spatial privacy at all-assiduously and constantly recreate new ways of being. The tools used to 'manage' menstruation promoted by MHM initiatives-biomedical knowledge, single-use absorbents, access to toilets and water sources-are important, but seem to occupy a world apart from Champa's, whose management techniques rely on kinship and relationality. By rendering menstruation a technical, hygienic crisis these initiatives at best ignore and at worst stigmatize the very things that make menstruation meaningful in the lives of women and girls in informal settlements.

\section{Notes}

1. We will endeavor to use the gender-neutral language of menstruators throughout this paper, to avoid gender essentialism and acknowledge what Chris Bobel $(2010,164)$ refers to as the "inclusion fundamental to third-wave feminism." But also, and perhaps more significantly, given the subject matter of this paper, we use this language to acknowledge the extent to which global inequalities of calorie intake, access to medical care, housing, and working conditions mean that menstruation can by no means be assumed or presumed to flow naturally and regularly from all bodies sexed female of reproductive age.

2. We borrow the language of indicators from Sally Engle Merry's work, specifically The Seductions of Quantification: Measuring Human Rights, Gender Violence, and Sex Trafficking (2016).

3. Tania $\operatorname{Li}(2007,7)$ reminds us, "the practice of 'rendering technical' confirms expertise and constitutes the boundary between those who are positioned as trustees, with the capacity to diagnose deficiencies in others, and those who are subject to expert direction." 
4. WASH is a widely used development acronym that stands for water, sanitation and hygiene.

5. Both the words $j h u g g \bar{\imath}$ and $j h o p r i \overline{~ a r e ~ u s e d ~ t o ~ d e s c r i b e ~ a n ~ i n d i v i d u a l ~ d w e l l i n g ~}$ within a slum settlement with the phrase jhuggi jhoprī cluster or JJ cluster being used to describe the settlement itself.

6. In 2015 the Central Bureau of Investigation (CBI) in an affidavit to the supreme court stated that there were 29.9 lakh or almost 3 million NGOs registered in India under the Society Registration Act (Rajagopal 2015). 76,566 of these NGOs were registered in Delhi-constituting roughly one registered NGO for every 248 people.

7. Inter-generational conflicts and claims to expertise around hygiene, dominated many children's responses to the handwashing campaign observed by McCarthy (2015) during her fieldwork.

\section{REFERENCES}

Appadurai, Arjun. 2004. "The Capacity to Aspire: Culture and the Terms of Recognition." In Culture and Public Action, edited by V. Rao and M. Walton. Stanford: Stanford University Press.

Arnold, David. 1993. Colonising the Body: State Medicine and Epidemic Disease in Nineteenth-Century India. Berkeley: University of California Press.

Baviskar, Amita. 2003. "Between Violence and Desire: Space, Power, Identity in the Making of Metropolitan Delhi." International Social Science Journal 55 (175): 89-98.

Bhan, G. 2009. “'This Is No Longer the City I Once Knew': Evictions, the Urban Poor and the Right to the City in Millennial Delhi." Environment and Urbanisation 21 (1): 127-42.

Bhattacherjee, Sharmistha, Kuntala Ray, Romy Biswas, and Manasi Chakraborty. 2013. "Menstruation: Experiences of Adolescent Slum Dwelling Girls of Siliguri City, West Bengal, India." Journal of Basic and Clinical Reproductive Sciences 2 (2): 85-91.

Bobel, Chris. 2010. New Blood: Third-Wave Feminism and the Politics of Menstruation. New Brunswick: Rutgers University Press.

- 2019. The Managed Body: Developing Girls \& Menstrual Health in the Global South. Cham, Switzerland: Palgrave Macmillan.

Chakraborty, Kabita. 2010. "The Sexual Lives of Muslim Girls in the Bustees of Kolkatta, India." Sex Education: Sexuality, Society and Learning 10 (1): 1-21.

Dasgupta, A., and M. Sarkar. 2008 "Menstrual Hygiene: How Hygienic Is the Adolescent Girl?” Indian Journal of Community Medicine 33 (2): 77-80.

Datta, Ayona. 2008. "Spatialising Performance: Masculinities and Femininities in a 'Fragmented' Field." Gender, Place and Culture 15 (2): 189-204.

—. 2012 The Illegal City: Space, Law and Gender in a Delhi Squatter Settlement. Surrey: Ashgate.

Van Eijk, Anna Maria, M. Sivakami, Mahmita Bora Thakkar, Ashley Bauman, Kayla F. Laserson, Susanne Coates, and Penelope A. Phillios-Howard. 2016. "Menstrual Hygiene Management among Adolescent Girls in India: A Systematic Review and Meta-analysis.” BMJ Open 6. https://doi.org/10.1136/bmjopen-2015-010290. 
Fadnis, Deepa. 2017. "Feminist Activists Protest Tax on Sanitary Pads: Attempts to Normalize Conversations about Menstruation in India Using Hashtag Activism." Feminist Media Studies 17 (41): 1-4.

Fingerson, Laura. 2006. Girls in Power: Gender, Body and Menstruation in Adolescence. New York: State University of New York Press.

Gan, Wendy. 2009. Women, Privacy and Modernity in Early Twentieth-Century British Writing. London: Palgrave Macmillan.

Ghertner, Asher. 2015. Rule by Aesthetics: World-Class City Making in Delhi. New York: Oxford University Press.

Jewitt, Sarah, and Harriet Ryley. 2014. “It's a Girl Thing: Menstruation, School Attendance, Spatial Mobility and Wider Gender Inequalities in Keynya." Geoforum 56: $137-47$.

Joshi, Deepa, Ben Fawcett, and Fouzia Mannan. 2011. "Health, Hygiene and Appropriate Sanitation: Experiences and Perceptions of the Urban Poor." Environment and Urbanization 23 (1): 91-111.

Kumar, Anant, and Kamiya Srivastava. 2011. "Cultural and Social Practices Regarding Menstruation among Adolescent Girls." Social Work in Public Health 26 (6): 594-604.

Lahiri-Dutt, Kuntala. 2015. "Medicalising Menstruation: A Feminist Political Economic Critique of Menstrual Hygiene Management in South Asia." Gender, Place and Culture: A Journal of Feminist Geography 22 (8): 1158-776.

Li, Tania. 2007. The Will to Improve: Governmentality, Development, and the Practice of Politics. Durham: Duke University Press.

Mahon, T., and M. Fernandes. 2010. "Menstrual Hygiene in South Asia: A Neglected Issue for WASH (Water, Sanitation and Hygiene) Programs." Gender and Development 18 (1): 99-113.

Martin, Emily. 1999. "The Woman in the Flexible Body." In Revision Women, Health and Healing: Feminist, Cultural and Technoscience Perspectives, edited by A. Clarke and V. L. Olesen. New York: Routledge.

McCarthy, Annie. 2015. "Telling Stories, Washing Hands: Exploring the Role of Narrative in Development Programs Targeting Children." South Asian History and Culture 6 (3): 401-16.

Merry, Sally Engle. 2016. The Seductions of Quantification: Measuring Human Rights, Gender Violence, and Sex Trafficking. Chicago: University of Chicago Press.

Mohanty, Chandra Talpade. 1984. "Under Western Eyes: Feminist Scholarship and Colonial Discourses." boundary 212 (3): 333-58.

Moore, B., Jr. 1984. Privacy: Studies in Social and Cultural History. London: Pantheon Books.

Mukhopadhyay, Bhaskar. 2006. "Crossing the Howrah Bridge: Calcutta, Filth, and Dwelling-Forms, Fragments, Phantasms." Theory, Culture and Society 23: 221-41.

Penner, Barbara. 2010. "Flush with Inequality: Sanitation in South Africa." Places Journal, November. https://placesjournal.org/article/ flush-with-inequality-sanitation-in-south-africa/.

Phillips-Howard, Penelope A., Bethany Caruso, Belen Torondel, Garazi Zulaika, Murat Sahin, and Marni Sommer. 2016. "Menstrual Hygiene Management among Adolescent Schoolgirls in Low- and Middle-Income Countries: Research Priorities." Global Health Action 9 (1): 33032. 
Prasanna, Chitra Karunakaran. 2016. "Claiming the Public Sphere: Menstrual Taboos and the Rising Dissent in India." Agenda: Empowering Women for Gender Equity 30 (3): 91-95.

Prashad, Vijay. 2001 "The Technology of Sanitation in Colonial Delhi." Modern Asian Studies 35 (1): 113-15.

- 2002. Untouchable Freedom: A Social History of a Dalit Community. New Delhi: Oxford University Press.

Puri, Jyoti. 1999. Woman, Body, Desire in Post-Colonial India: Narratives of Gender and Sexuality. New York: Routledge.

Rajagopal, K. 2015. "Only 10\% of NGOs Have Filed Financial Details with Govt: CBI to SC." The Hindu, September 18. https://www.thehindu.com/news/ national/only-10-ngos-have-filed-financial-details-with-govtcbi-to-sc/article7665565.ece.

Rajagopal, Shobita, and Kanchan Mathur. 2017. "Breaking the Silence around Menstruation: Experiences of Adolescent Girls in an Urban Setting in India.” Gender and Development 25 (2): 303-17.

Reddy, B. S., and M. Snehalatha. 2011. "Sanitation and Personal Hygiene What Does It Mean to Poor and Vulnerable Women?" Indian Journal of Gender Studies 18 (3): 381-404.

Sommer, Marni. 2010. "Where the Education System and Women's Bodies Collide: The Social and Health Impact of Girls' Experiences of Menstruation and Schooling in Tanzania." Journal of Adolescence 33 (4): 521-29.

Sumpter, C., and B. Torondel. 2013. "A Systematic Review of the Health and Social Effects of Menstrual Hygiene Management.” PLoS One 8 (4): e62004.

Talukdar, Jaitar. 2014. "Rituals and Embodiment: Class Differences in Religious Fasting Practices of Bengali Hindu Women.” Sociological Focus 47: 141-62.

Truelove, Yaffa. 2011. "(Re-)Conceptualizing Water Inequality in Delhi, India through a Feminist Political Ecology Framework." Geoforum 42: 143-52.

USAID, Kiawah Trust and Dasra. 2014. Spot On! Improving Menstrual Hygiene in India. https://www.dasra.org/cause/improving-menstrual-health-and-hygiene.

Water Supply and Sanitation Collaborative Council and Governmnet of India. 2013. WASH and Health for Menstrual Hygiene Mangagement: Traing of Trainers Maunal, v1.0. https://www.wsscc.org/resources-feed/training-of-trainers-manualwash-and-health-for-menstrual-hygiene-management/.

Zaidi, Syed Hasan Nawaz, A. Sivakami, and D. Jegadeesh Ramasamy. 2015. "Menstrual Hygiene and Sanitation Practices among Adolescent School Going Girls: A Study from a South Indian Town." International Journal of Community Medicine and Public Health 2 (2): 189-94. 
Open Access This chapter is licensed under the terms of the Creative Commons Attribution 4.0 International License (http://creativecommons.org/licenses/ by $/ 4.0 /)$, which permits use, sharing, adaptation, distribution and reproduction in any medium or format, as long as you give appropriate credit to the original author(s) and the source, provide a link to the Creative Commons license and indicate if changes were made.

The images or other third party material in this chapter are included in the chapter's Creative Commons license, unless indicated otherwise in a credit line to the material. If material is not included in the chapter's Creative Commons license and your intended use is not permitted by statutory regulation or exceeds the permitted use, you will need to obtain permission directly from the copyright holder. 